Article

\title{
Adjusting the Morphology and Properties of SiC Nanowires by Catalyst Control
}

\author{
Chuchu Guo, Laifei Cheng, Fang Ye and Qing Zhang * \\ Science and Technology on Thermostructural Composite Materials Laboratory, \\ Northwestern Polytechnical University, West Youyi Rd, No. 127, Xi'an 710072, China; \\ ccguo@mail.nwpu.edu.cn (C.G.); chenglf@nwpu.edu.cn (L.C.); yefang511@nwou.edu.cn (F.Y.) \\ * Correspondence: zhangqing@nwpu.edu.cn
}

Received: 19 October 2020; Accepted: 10 November 2020; Published: 17 November 2020

\begin{abstract}
We report on the growth of $\mathrm{SiC}$ nanowires on a single crystal Si substrate by pyrolysis of polycarbosilane and using two catalyst $\left(\mathrm{Al}_{2} \mathrm{O}_{3}\right.$ and $\left.\mathrm{Ni}\right)$ films with different thickness $(2,4$, and $6 \mathrm{~nm})$. The catalyst films were deposited on the $\mathrm{Si}$ substrate, and the $\mathrm{SiC}$ nanowires were grown according to two mechanisms, i.e., the oxide-assisted growth mechanism and vapor- liquid-solid mechanism. As a result, pearl-chain-like $\mathrm{SiC}$ nanowires and straight $\mathrm{SiC}$ nanowires were obtained. The prepared nanowires exhibited excellent photoluminescence properties, emission spectra displaying two emission peaks at 395 and $465 \mathrm{~nm}$, and have good thermal stability below $1000^{\circ} \mathrm{C}$. The experimental results revealed the importance of the catalyst in controlling the morphology and properties of $\mathrm{SiC}$ nanowires.
\end{abstract}

Keywords: silicon carbide nanowires; vapor-solid-liquid mechanism; oxide-assisted growth mechanism; photoluminescence; thermal stability

\section{Introduction}

In the nanometer scale, the surface effect, small size effect, quantum size effect and macroscopic tunneling effect dramatically change the physical and chemical properties of materials [1-4]. For instance, $\mathrm{SiC}$ nanowires, a non-oxide ceramic material, attracted great interest as a highly promising nanomaterial for many industrial applications due to their superior electric and mechanical properties, as well as heat, corrosion, and high temperature oxidation resistance [5-7]. These unique properties enable $\mathrm{SiC}$ nanowires to be used as ideal candidates for nanodevices for sensing and biosensing applications, or in composite materials as a reinforcement [8-10]. To the key role, SiC nanowires are widely used in aerospace, nuclear, braking systems and other industrial fields [11-13]. The development of high-performance materials and the maturity of preparation technology have stimulated researchers to design and create the $\mathrm{SiC}$ nanowires with higher performance, which further promoted deeper research on the growth mechanism of $\mathrm{SiC}$ nanowires.

Oxides are commonly used as catalysts to grow nanowires through the oxide-assisted growth (OAG) mechanism, whereas transition metals are often used as catalysts for the growth of nanomaterials by the vapor-liquid-solid (VLS) mechanism. Zhang [14] studied the growth of Si nanowires with uniform size and long length by OAG and VLS mechanisms, aiming at achieving a controlled growth of nanowires. Kang [15] used Au catalyst to prepare III-V semiconductor nanowires with a certain angle and extended (111) direction on the (001) Si substrate by the VLS mechanism. Zhang [16] prepared bamboo-like $\mathrm{SiC}$ nanowires by doping $\mathrm{Al}$ catalyst during the pyrolysis of polycarbosilane (PCS). The findings highlighted the positive role played by the catalyst during the growth of semiconductor and oxide nanowires. Wang [17] reported the synthesis of a Si nanowire structure, using tin particles as a catalyst, and by adjusting the periodic volume change of the catalyst, liquid tin segments periodically 
appeared in the Si nanowires during the growth process. The results clearly show that this abnormal growth is controlled by the dual effects of VLS and OAG. In the process of preparing Si nanowires, M. Agati [18] discovered that the nanowires are grown catalyzed by a silicon core (with a diameter of 2 nanometers) and a silicon shell. The combination of advanced transmission electron microscopy technology proved that the growth of long Si nanowires is carried out by the OAG mechanism, while the growth of shorter Si nanowires is carried out by the VLS mechanism. Wang [19] uses the electron beam evaporation method under ultra-high pressure to prepare one-dimensional silicon nanowires. The results show that during the VLS growth process, Si nanowires can be formed on the Si surface, but $\mathrm{Si}$ nanowires cannot be formed on the $\mathrm{SiO}_{2}$ surface. But in the OAG process, $\mathrm{Si}$ nanowires can grow on the surface of $\mathrm{SiO}_{2}$. Nevertheless, only a few reports on the growth of $\mathrm{SiC}$ nanowires in the presence of catalysts and different growth mechanisms are available in the literature.

This work is focused on the preparation of $\mathrm{SiC}$ nanowires, displaying different morphologies, by changing the type and content of catalysts loaded on the substrate. The nanowires were grown on the single crystal silicon substrate by VLS and OAG mechanisms. The phase composition, microstructure, and morphology, as well as the photoluminescence properties and thermal stability of the prepared $\mathrm{SiC}$ nanowires were analyzed. The growth mechanisms of SiC nanowires were described in detail, providing fundamental knowledge for the rational control of the morphology of SiC nanowires.

\section{Experimental}

\subsection{Synthesis of Samples}

The $30 \mathrm{wt.} \%$ PCS precursor (Xiamen University) was mixed with xylene under magnetic stirring for $30 \mathrm{~min}$. A multifunctional ion beam assisted deposition (IBAD) device is adopted. The pressure during the deposition process: $2.5 \times 10^{-2} \mathrm{~Pa} 3.2 \times 10^{-2} \mathrm{~Pa}$, the ion beam energy is $600 \mathrm{eV}$, and the deposition rate is $0.05 \mathrm{~nm} / \mathrm{s}$. The deposition time is controlled to obtain nano-films of different thicknesses $(2 \mathrm{~nm}$, $4 \mathrm{~nm}$ and $6 \mathrm{~nm}$ ), and the preparation of the catalyst film is characterized by the weight gain and surface morphology of the substrate. The main components of the target (wt.\%) are: $99.99 \% \mathrm{Ni}$ and $\mathrm{Al}_{2} \mathrm{O}_{3}$. The basic material is a single crystal $\mathrm{Si}(111)$ wafer, and the substrate temperature is lower than $100^{\circ} \mathrm{C}$ during the deposition process. The precursor was then poured into a crucible, which was transferred to a tube furnace. The substrate with catalyst film was placed downstream $5 \mathrm{~cm}$ from the precursor. The air in the furnace was replaced with Ar gas at a flow rate of 40 SCCM (standard cubic centimeter per minute). The temperature was raised to 1350 at a rate of $5{ }^{\circ} \mathrm{C} / \mathrm{min}$ and held for $3 \mathrm{~h}$. The obtained products were named as $\mathrm{A} 1, \mathrm{~A} 2, \mathrm{~A} 3$, respectively for the samples prepared with $\mathrm{Al}_{2} \mathrm{O}_{3}$ catalyst film at a thickness of 2, 4, and $6 \mathrm{~nm}$, and N1, N2, N3, respectively for the samples prepared with Ni catalyst film at a thickness of 2,4 , and $6 \mathrm{~nm}$.

\subsection{Characterization of Samples}

The obtained $\mathrm{SiC}$ nanowires were coated with a $5 \mathrm{~nm}$ layer of gold for scanning electron microscopy (SEM) imaging. The images were taken using a field emission scanning electron microscope (FE-SEM, S-4700, Tokyo, Japan). Samples were also observed by transmission electron microscopy (TEM) using a FEI Talos F200X microscope (Hillsboro, OR, USA). Crystal phases were characterized by an X-ray diffractometer (X-ray diffraction, XRD, AXS D8, Karlsruhe, Germany) via grazing incidence mode with an incidence angle of $2^{\circ}$, and MDI Jade software (California City, CA, USA) was used for fitting calculation of crystallization rate and crystallite size as an auxiliary method to analyze the evolution of sample structure and phase composition by using the following equations:

$$
\begin{gathered}
\text { Crystallinit }=\frac{\text { diffraction peak strength }}{\text { total strength }} \times 100 \% \\
\text { Crystallite size }=\frac{\mathrm{K} \lambda}{\mathrm{FW}(\mathrm{S}) \cos \theta}
\end{gathered}
$$


$\mathrm{K}$ is a constant, $\lambda$ is the wavelength of an $\mathrm{X}$-ray, $\mathrm{FW}(\mathrm{S})$ is the width of the sample, and $\theta$ is the diffraction Angle.

The photoluminescence properties were characterized by X-ray fluorescence spectrometry (Axios-X, Almelo, Netherlands), and the thermal stability of the samples was measured with thermogravimetric analysis-differential scanning calorimetry (TG-DSC) equipment at $10{ }^{\circ} \mathrm{C} / \mathrm{min}$ to $1400^{\circ} \mathrm{C}$ air atmosphere (GCMS QP2010 PLUS, Waltham, MA, USA).

\section{Results and Discussion}

The morphology and growth mechanism of SiC nanowires were controlled by using different catalysts. The corresponding surface and cross-section morphology SEM images of all six samples are illustrated in Figures 1 and 2.
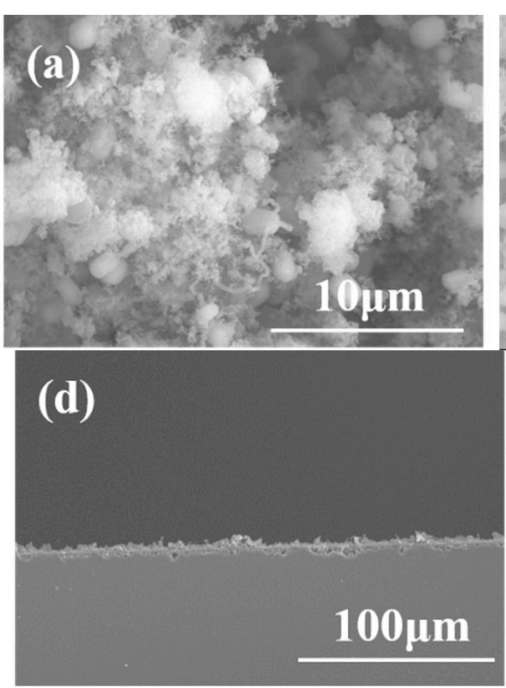
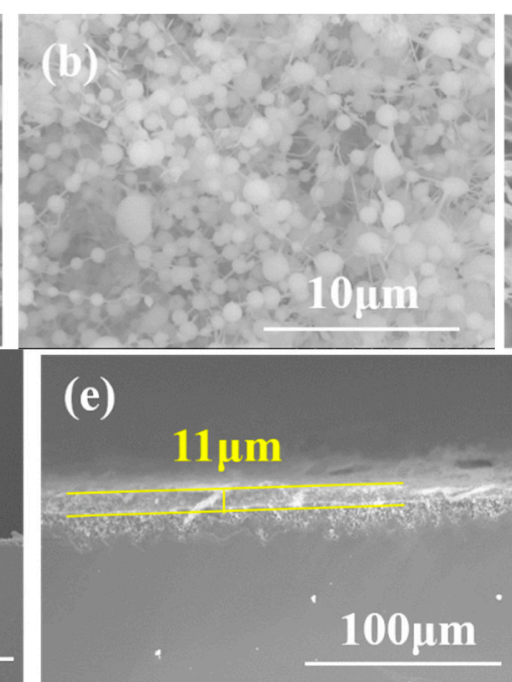
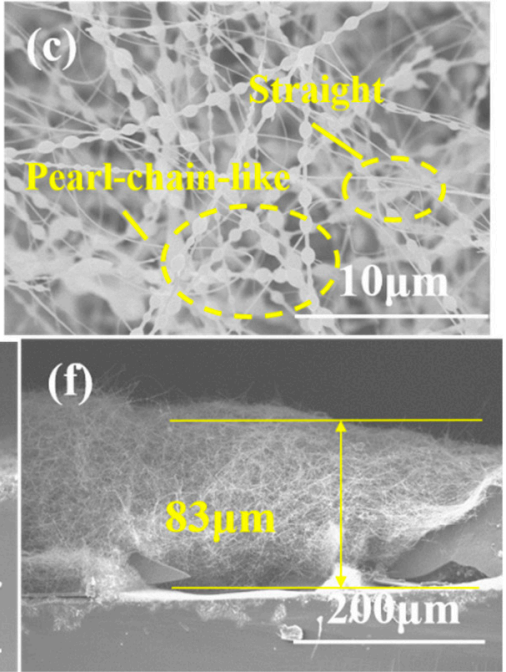

Figure 1. Surface morphology scanning electron microscopy (SEM) images of (a) A1, (b) A2, (c) A3 SiC nanowires, Cross-section morphology SEM images of (d) A1, (e) A2, (f) A3 SiC nanowires.
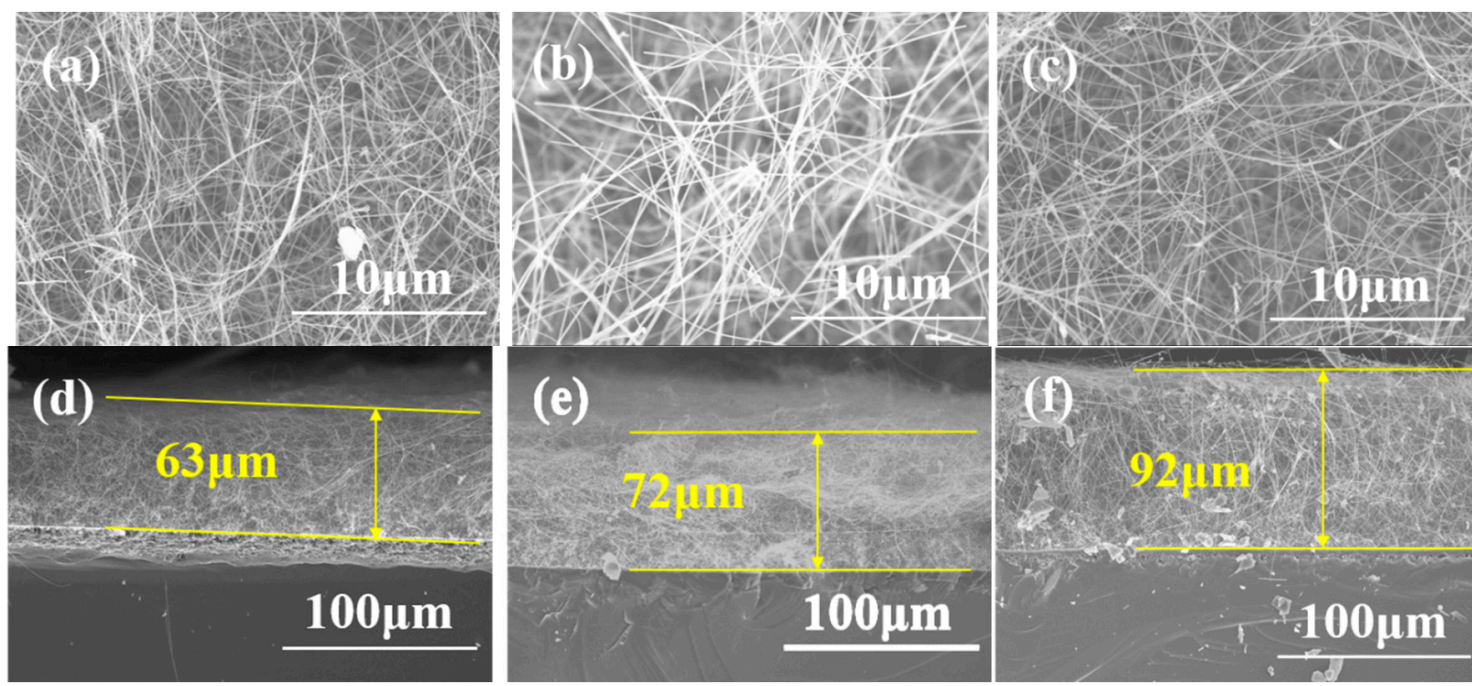

Figure 2. Surface morphology SEM images of (a) N1, (b) N2, (c) N3 SiC nanowires, Cross-section morphology SEM images of (d) N1, (e) N2, (f) N3 SiC nanowires.

As shown in Figure 1a, when the thickness of the $\mathrm{Al}_{2} \mathrm{O}_{3}$ catalyst is $2 \mathrm{~nm}$, a large number of pearl-like beads are formed on the surface of the substrate, which are in intimate contact with the surface (Figure 1d). As the thickness of the catalyst film increases, $\mathrm{SiC}$ nanowires begin to form, but they 
are straight and co-exist with the pearl-chain-like nanowires (Figure 1b,c). Also, the thickness of the nanowire on the substrate surface becomes larger which obviously increased from 11 to $85 \mu \mathrm{m}$ for the samples prepared with the $\mathrm{Al}_{2} \mathrm{O}_{3}$ film thickness of 4 and $6 \mathrm{~nm}$, respectively (Figure 1e,f). The diameter of the straight nanowire is about $50 \mathrm{~nm}$. The minimum diameter of the pearl-chain-like nanowire is about $100 \mathrm{~nm}$, and the maximum diameter of the pearls is about $850 \mathrm{~nm}$. The SEM images of the samples prepared with $\mathrm{Ni}$ catalyst are illustrated in Figure 2. As observed, the diameter of the $\mathrm{SiC}$ nanowires catalyzed by Ni film is about $50 \mathrm{~nm}$ while their surface is smooth and clean (Figure 2a-c). The cross-section image (Figure 2d) shows a mats-like arrangement of the nanowires on the substrate. As the thickness of the Ni catalyst increases to 4 and $6 \mathrm{~nm}$, the thickness of nanowires increases from 63 to $92 \mu \mathrm{m}$, respectively, while the layer of nanowires is denser (Figure 2e,f). These results indicate that different growth mechanisms of the nanowires in the presence of the two catalysts. For A1, A2, and A3 samples, amorphous shells were observed on the surface of nanowires. This is a typical feature of the OAG growth mechanism, so it can be concluded that nanowires grow in accordance with the OAG growth mechanism [20-22]. In this case, the growth of $\mathrm{SiC}$ nanowires is assisted by semi-liquid $\mathrm{Al}_{2} \mathrm{O}_{3}$ when an $\mathrm{Si}-\mathrm{O}-\mathrm{Al}$ amorphous layer is formed on the surface of the nanowires, preventing the lateral growth of the nanowires. By contrast, the growth mechanism of the nanowires in N1, N2, and N3 samples is the VLS mechanism. In this case, the catalyst droplets form at lower temperatures. The catalyst droplet can be used as a template to control the morphology of the $\mathrm{SiC}$ nanowire at the top of the nanowire. Secondly, the solid-liquid interface is formed at the top of the nanowires, so that the reactants continue to crystallize at the interface to form nanowires.

Figure 3 displays the XRD patterns of $\mathrm{SiC}$ nanowires grown in the presence of the two different catalysts.
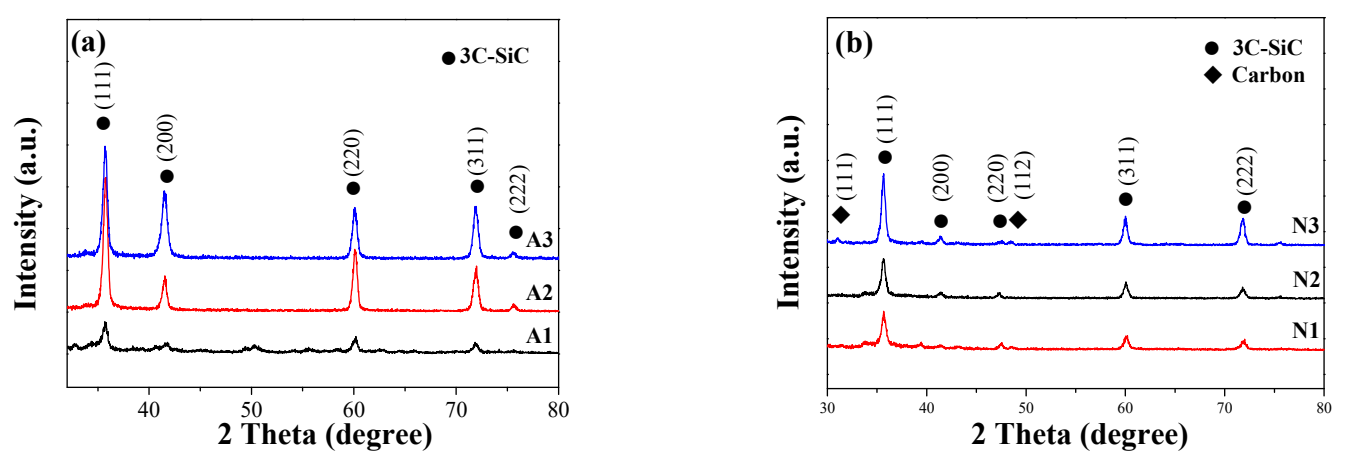

Figure 3. X-ray diffraction (XRD) patterns of $\mathrm{SiC}$ nanowires prepared with (a) $\mathrm{Al}_{2} \mathrm{O}_{3},(\mathbf{b}) \mathrm{Ni}$ catalysts.

As illustrated in Figure 3a, all three samples showed typical diffraction peaks for 3C-SiC. When the thickness of $\mathrm{Al}_{2} \mathrm{O}_{3}$ is $2 \mathrm{~nm}$, the characteristic peak strength of $\mathrm{SiC}$ is extremely weak. As the thickness of the $\mathrm{Al}_{2} \mathrm{O}_{3}$ catalyst film increases, the characteristic peaks of $\mathrm{SiC}$ gradually become sharp and clearly visible. This indicates that the catalyst increases, the amount of nanowires is larger or the crystallinity gradually increases. In Figure $3 b$, the typical diffraction peaks of $\mathrm{SiC}$ are displayed even at the lower thickness of the Ni film. However, the peaks become sharper as the thickness of the Ni film increases. To note, for the N3 sample, traces of C can be observed in the XRD pattern. The comparison of the crystallinity of samples reveals that a crystallization degree of $22.3 \%$ is obtained for the N3 sample, which is made of crystallites of $14.3 \mathrm{~nm}$, whereas a crystallinity degree of $35.6 \%$ is determined for the A3 sample, consisting of crystallites of $21.1 \mathrm{~nm}$ (Table 1). This result is consistent with the SEM result. The sample with $\mathrm{Al}_{2} \mathrm{O}_{3}$ as catalyst has a larger diameter, so the overall crystallinity is higher. This is because the semi-liquid catalyst in the OAG growth mechanism is only attached to the surface of $\mathrm{SiC}$ nanowires, and the limiting force on the diameter of nanowires is weaker than that on the tip of the nanowire droplets in the VLS mechanism. 
Table 1. Crystallinity and crystallite size of $\mathrm{SiC}$ nanowires grown on the substrate surface in the presence of $\mathrm{Ni}$ or $\mathrm{Al}_{2} \mathrm{O}_{3}$ as catalysts.

\begin{tabular}{ccc}
\hline Sample & Crystallinity/\% & Crystallite Size/nm \\
\hline A3 & 35.6 & 21.1 \\
N3 & 22.3 & 14.3 \\
\hline
\end{tabular}

The microstructure and composition of the A3 sample are analyzed by high-resolution transmission electron microscopy (HRTEM), selected area electron diffraction (SAED), and energy-dispersive spectroscopy (EDS). The results are displayed in Figure 4.

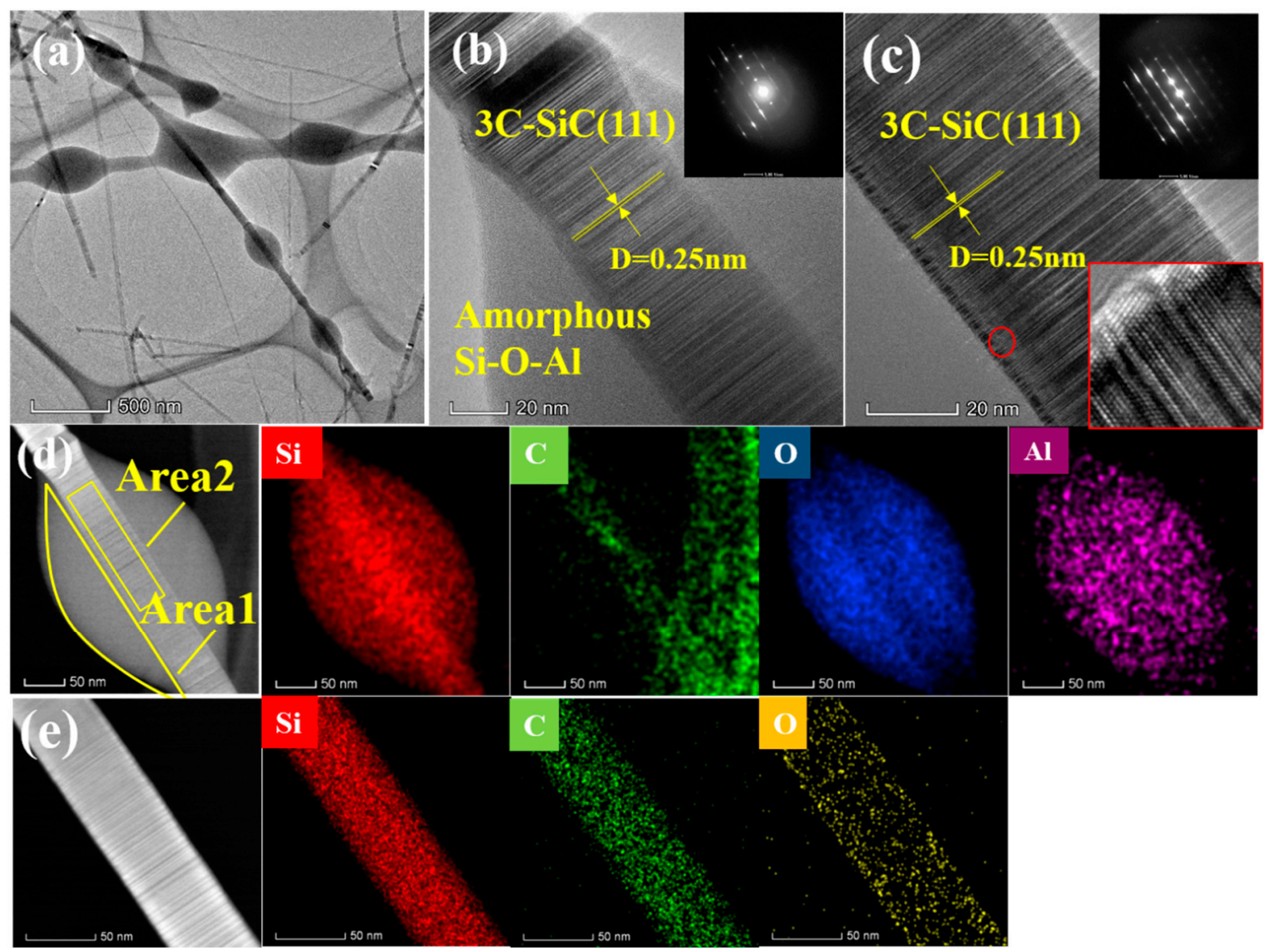

Figure 4. (a) Transmission electron microscope (TEM) image of A3 sample, (b) high-resolution transmission electron microscope (HRTEM) image and selected area electron diffraction (SAED) pattern of pearl-chain-like nanowire, (c) HRTEM image and SAED pattern of straight nanowire. (d) Energy-dispersive spectroscopy (EDS) mapping of pearl-chain-like nanowire; (e) EDS mapping of straight nanowire.

Figure 4 shows representative HRTEM images of the A3 sample. It can be observed that two different morphologies co-exist in the sample, a bead-like morphology as well as a smooth and straight-shaped morphology (Figure 4a). The pearl-like beads of $\sim 150 \mathrm{~nm}$ in diameter, which are placed alongside the nanowire, are amorphous. The core of the beads is crossed by a straight nanowire with a diameter of $50 \mathrm{~nm}$. The $d$-spacing between two neighboring lattice fringes is $0.25 \mathrm{~nm}$, according to Figure $4 \mathrm{~b}$. It can be observed from the SAED in the Figure $4 \mathrm{~b}$ inset, that the crystal diffraction lattice co-exists with a halo, attributed to the amorphous phase. Hence, it can be stated that the core of the pearl-like beads is made of a SiC single crystal while the pearl-like structure is amorphous. From Figure 4c, it can be observed that the straight SiC nanowires, having a diameter of $50 \mathrm{~nm}$, 
are grown in the (111) direction. In addition, defects such as twin defects can be observed inside the nanowires by magnifying high resolution images in red circles (Figure 4c). The EDS pattern of pearl-chain-like nanowire clearly shows that the amorphous layer mainly contains $\mathrm{Si}, \mathrm{O}$, and $\mathrm{Al}$ (Figure $4 \mathrm{~d}$ ). As listed in Table 2, in the Area 1, the amorphous Si-O ratio is close to 1:2 while a small amount of $\mathrm{Al}$ is also detected. The $\mathrm{Si}-\mathrm{C}$ ratio of Area 2 is close to 1 , and the atomic content of oxygen is $2.65 \%$, indicating that the core of the nanowire is composed of $3 \mathrm{C}-\mathrm{SiC}$ single crystals. The microstructure and composition of the smooth and straight nanowires in A3 are the same as the core of the beads discussed above (Figure $4 \mathrm{e}$ ).

Table 2. Elemental analysis results of different regions in A3 displayed in Figure 4d.

\begin{tabular}{rccccc}
\hline & Element & Si & C & O & Al \\
Atomic Fraction (\%) & 29.53 & 2.06 & 63.39 & 5.01 \\
Area 1 & 52.81 & 44.54 & 2.65 & - \\
Area 2 & & & &
\end{tabular}

Since no other metal elements participate in the reactions during the synthesis, but only $\mathrm{Al}_{2} \mathrm{O}_{3}$, it is evident that the nucleation and growth of the A1, A2, and A3 samples are governed by the OAG mechanism. Figure 5 schematically illustrates the growth of $\mathrm{SiC}$ nanowires in the presence of the $\mathrm{Al}_{2} \mathrm{O}_{3}$ catalyst via the OAG mechanism.

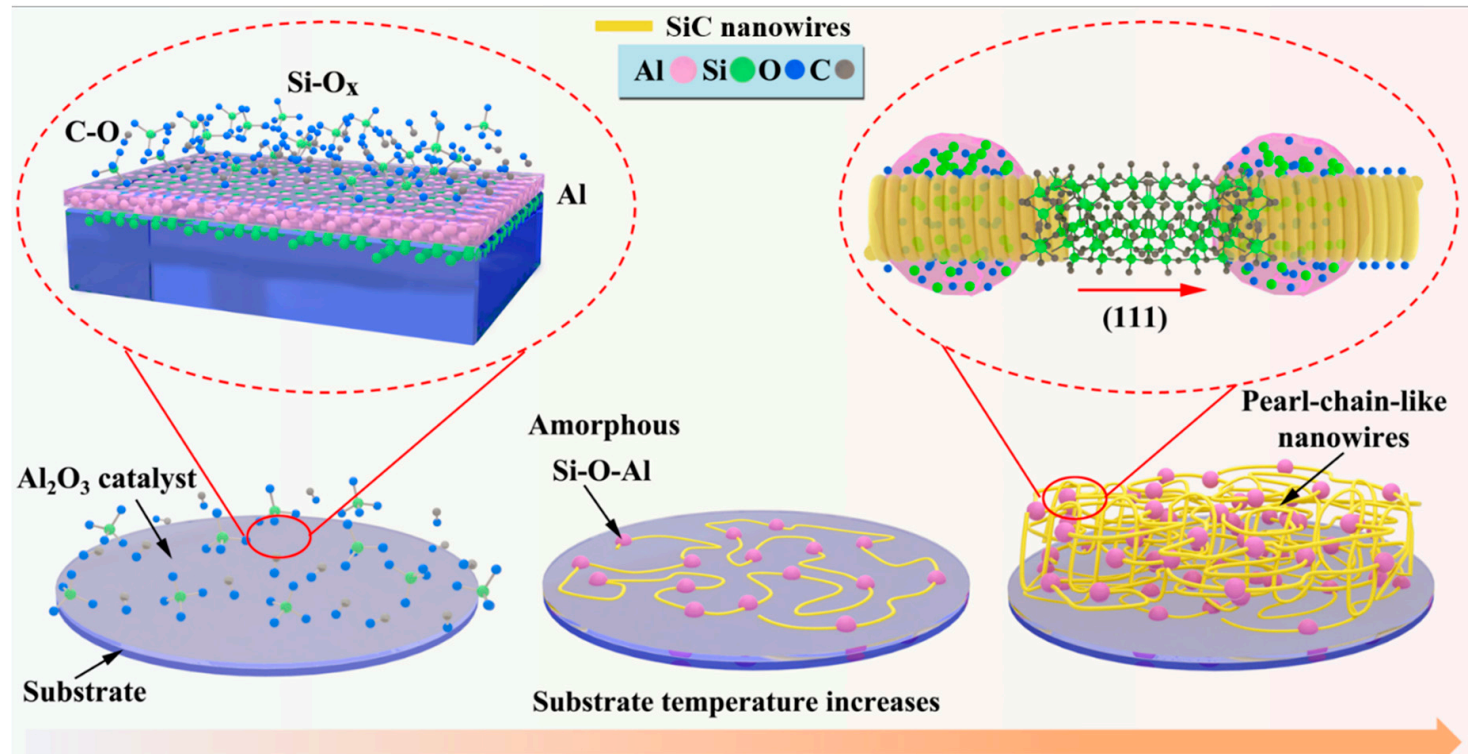

Figure 5. Schematic diagram of growth mechanisms of $\mathrm{SiC}$ nanowires loaded with $\mathrm{Al}_{2} \mathrm{O}_{3}$ catalysts.

In the initial stage of the reaction, the $\mathrm{Al}_{2} \mathrm{O}_{3}$ film deposited on the $\mathrm{Si}$ substrate is strongly bonded to the substrate, which limits the agglomeration of the catalyst on the substrate surface. The pyrolysis temperature of $1350{ }^{\circ} \mathrm{C}$ is very close to the melting point of the silicon wafer, which weakens the bonding force between the $\mathrm{Al}_{2} \mathrm{O}_{3}$ thin layer and the silicon wafer. The released reactive atoms react with the pyrolysis byproduct gas $\left(\mathrm{CO}\right.$ and $\left.\mathrm{SiO}_{\mathrm{X}}\right)$ of the PCS, the available bonds are directed toward the surface, and the diffused $\mathrm{Al}$ atoms form a $\mathrm{Si}-\mathrm{O}-\mathrm{Al}$ amorphous layer. This amorphous layer plays the role of adsorbent of reactive gases and promotes the formation of $\mathrm{SiC}$ nanowires with a certain crystal orientation. During the growth of $\mathrm{SiC}$ nanowires, the oxygen and aluminum atoms in $\mathrm{Si}-\mathrm{O}-\mathrm{Al}$ may be expelled by silicon atoms, which diffuse to the edges of the crystal and form amorphous protective shell, which also guides the growth direction of the nanowires. Therefore, the atomic content of oxygen in the pearl-shaped amorphous layer is as high as $63.39 \%$. Overall, the highly reactive Si-O-Al layer 
on the top of the $\mathrm{SiC}$ nanowire acts as a collector of gaseous $\mathrm{Si}-\mathrm{C}$, whereas the amorphous layer on the side of the nanowire prevents the increase of the nanowire diameter. Thus, a single crystal SiC nanowire with a straight center is formed. It is assumed that the twin defects of SiC nanowires are one of the driving forces of the growth along one direction. The existing twin dislocations in the growth direction and the formation of facets with low surface energy can also improve growth rate of nanowires along the (111) crystal plane. Twin steps are more likely to adsorb atoms. When the rate of amorphous adsorption in the reaction system is greater than the crystallization rate of $\mathrm{SiC}$, the pearl-like amorphous clusters appear on the nanowires, forming the pearl-chain nanowires.

Representative HRTEM images of N3 sample are depicted in Figure 6.

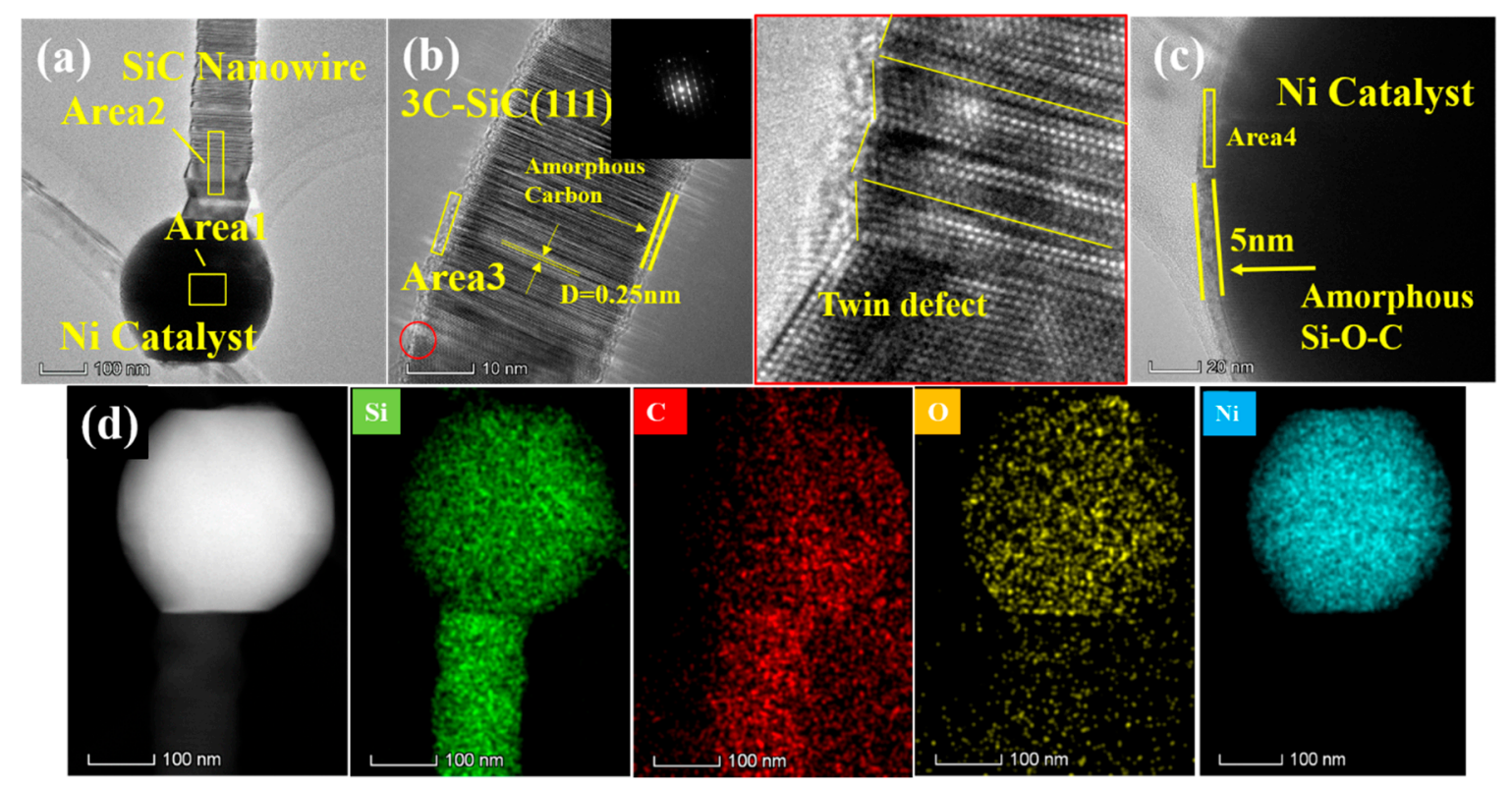

Figure 6. (a) TEM image of N3 sample; (b) HRTEM image and SAED pattern of nanowire; (c) HRTEM image of catalyst; (d) EDS mapping of N3 sample.

As can be seen from Figure $6 \mathrm{a}, \mathrm{Ni}$ catalyst is placed on the top of $\mathrm{SiC}$ nanowires, which is a typical feature of VLS mechanism [23-25]. This indicates that N1, N2 and N3 have grown according to the VLS mechanism [26,27]. The Ni catalyst controls the growth of SiC nanowires in the (111) direction. As shown, the average diameter of nanowires is $50 \mathrm{~nm}$ (Figure 6b). Many twin defects can be observed inside the nanowires, and a periodic sawtooth-shaped crystal structure of the $\mathrm{SiC}$ nanowires is noticed on the surface. As can be seen from the elemental analysis in Table 3 , the catalyst droplet mainly contains $77.76 \% \mathrm{Ni}$ and a small amount of $\mathrm{Si}, \mathrm{C}$ and $\mathrm{O}$ on the surface. The elemental composition of single crystal nanowires is mainly $\mathrm{Si}$ and $\mathrm{C}$ with atomic ratios close to 1:1, and $\mathrm{O}$ with $2.38 \%$. The amorphous layer coated on the surface of nanowires is mainly C. The SAED pattern shown in the illustration in Figure $6 \mathrm{~b}$ shows a single crystal lattice. The high-resolution image magnified in red circles shows defects in nanowire growth, such as twin defects. The high-resolution image in Figure $6 \mathrm{c}$ shows that the diameter of the Ni catalyst droplet is about $200 \mathrm{~nm}$. The surface of the droplet is covered by an amorphous layer of $\mathrm{Si}-\mathrm{O}-\mathrm{C}$ with a thickness of $5 \mathrm{~nm}$. The EDS spectrum of N3 shows that the catalyst droplets on the top of the nanowires are composed of $\mathrm{Si}, \mathrm{C}, \mathrm{O}$, and $\mathrm{Ni}$, whereas the Si-O-C mainly exists on the surface of the catalyst droplet (Figure 6d).

Figure 7 briefly illustrates the growth of SiC nanowires supported with Ni catalyst via the VLS mechanism. 
Table 3. Elemental analysis of different regions in N3 corresponding to Figure 6a,b.

\begin{tabular}{rccccc}
\hline & Element & Si & C & O & Al \\
Atomic Fraction (\%) & 12.91 & 7.79 & 1.54 & 77.76 \\
Area 1 & 49.05 & 48.57 & 2.38 & - \\
Area 2 & 11.68 & 79.43 & 8.89 & - \\
Area 3 & 48.24 & 44.85 & 6.92 & - \\
Area 4 & & &
\end{tabular}

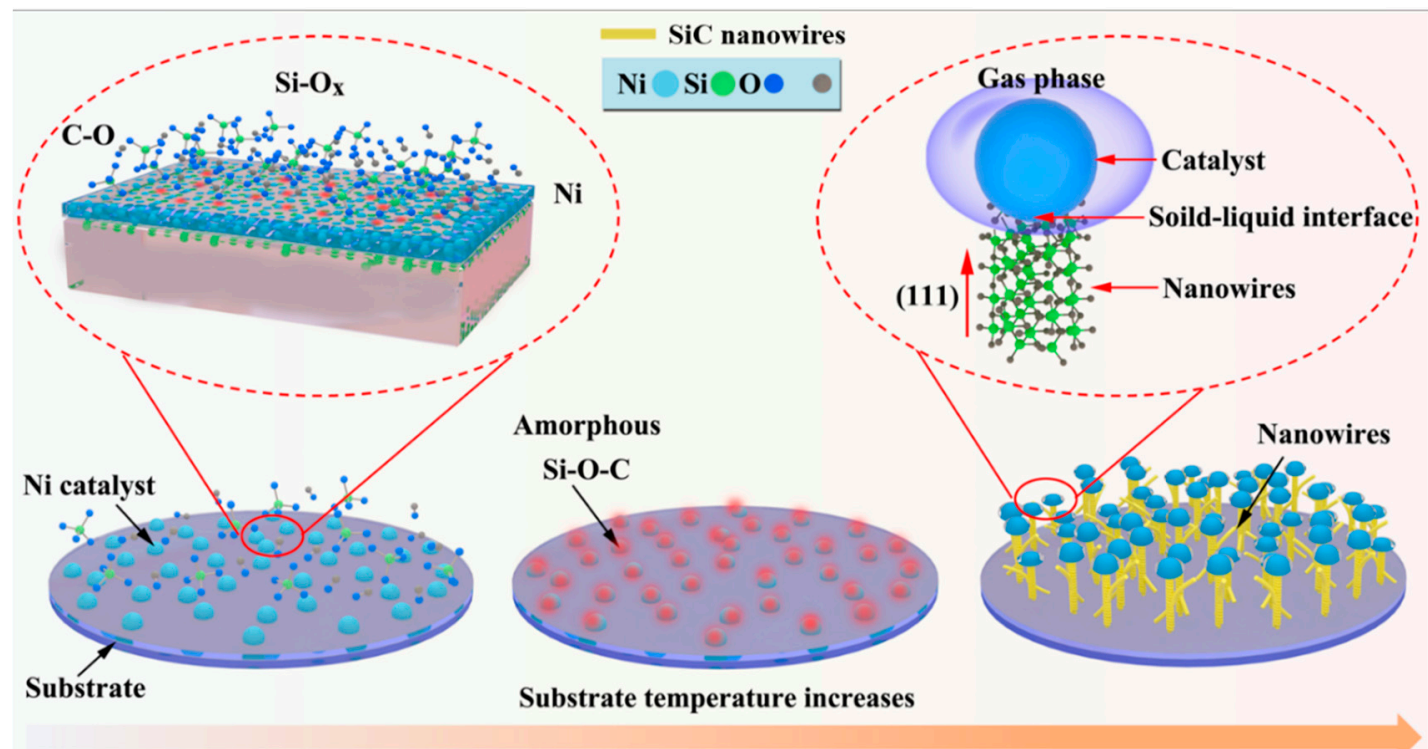

Figure 7. Schematic diagram of growth mechanisms of $\mathrm{SiC}$ nanowires loaded with Ni catalysts.

As the increase of substrate temperature, Ni first forms small droplets on the substrate surface, followed by the formation of a liquid-solid interface. Subsequently, the by-product gas formed during PCS pyrolysis is continuously adsorbed on the liquid-solid interface and promotes the crystallization of $\mathrm{Si}-\mathrm{O}-\mathrm{C}$ amorphous phase. The extra unreacted $\mathrm{C}$ is coated on the surface of nanowires, resulting in the formation of $\mathrm{SiC}$ single crystal nanowires. In addition, the lowest surface-energy (111) growth is allowed. Under these conditions, the increase in nanowire diameter is limited and the single-crystal SiC nanowires with straight morphologies are produced. It is different from the bead chain-like nanowire prepared by using $\mathrm{Al}_{2} \mathrm{O}_{3}$ as the catalyst.

Figure 8 illustrates the photoluminescence spectra of A3 and N3 samples.

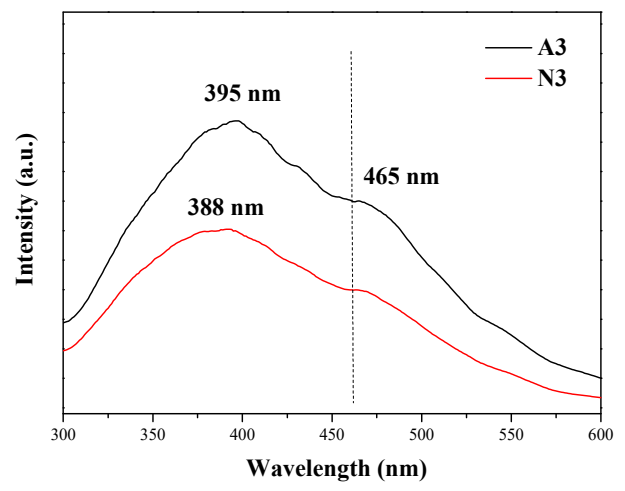

Figure 8. Photoluminescence spectra of A3 and N3 samples. 
As shown in Figure 8, the photoluminescent spectra at $350 \mathrm{~nm}$ of A3 and N3 display two obvious emission peaks at 395 and $465 \mathrm{~nm}$, corresponding to 3.13 and $2.67 \mathrm{eV}$, respectively. This indicates that the prepared 3C-SiC nanowires emit within a wide range of wavelengths. However, the intensity of the emission peaks varies according to the catalyst type. It is obvious that the morphology and structural defects influence the photoluminescence characteristics of nano-SiC crystals [28]. Herein, the shape of the emission peaks is largely similar, and the center position of the emission peak changes minimally. However, compared to the conventional $\mathrm{SiC}$ crystal with a relatively larger crystallite size for which the emission occurs at $556 \mathrm{~nm}$, a significant blue shift is noticed for both samples. At this point, the shape of the emission peak is basically similar, and the central position of the emission peak changes the least. However, the emission at $556 \mathrm{~nm}(2.39 \mathrm{eV})$ showed a significant blue shift in both samples when compared with conventional $\mathrm{SiC}$ crystals with a larger crystallite size. The emission peak of $\mathrm{SiC}$ nanowires at $465 \mathrm{~nm}$ has also been reported in other literature [29,30]. This can be explained by the quantum size effect, which is caused by the size constraint effect due to the small crystallite size and the displacement of emission peak due to the internal defect [31,32]. Compared with SiC crystals with larger crystallite size, single crystals with nanowire diameter of $\sim 100 \mathrm{~nm}$ were prepared. As previously observed, there are complex accumulation defects in silicon carbide nanowires. The other peak value is concentrated at $400 \mathrm{~nm}$, which is basically consistent with the values of 3C-SiC nanotubes [33] and $\mathrm{SiC}$ nanopores [32] The presence of a large number of amorphous phases in A3 leads to the formation of a bead chain with a diameter of $850 \mathrm{~nm}$, and the presence of amorphous elements also leads to the blue shift of the emission peak center [34].

The TG and DSC curves of A3 and N3 are displayed in Figure 9.
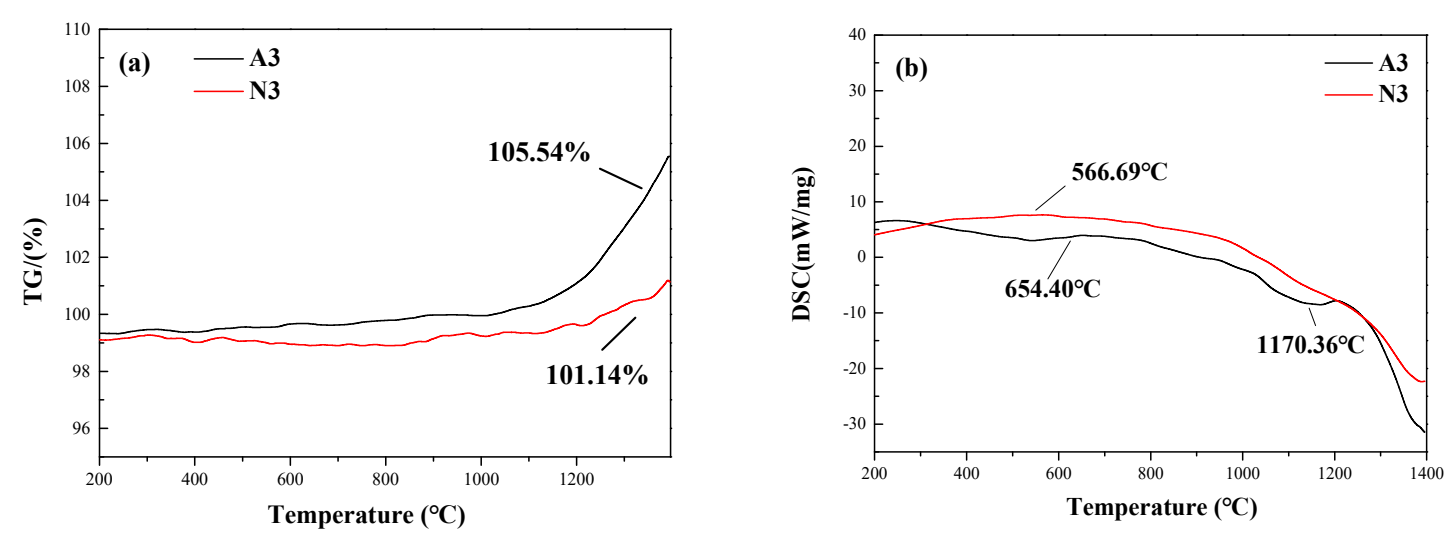

Figure 9. (a) Thermogravimetric (TG) and (b) differential scanning calorimetry (DSC) curves of A3 and N3 samples.

The TG curves show no change before $1100^{\circ} \mathrm{C}$. However, above $1100^{\circ} \mathrm{C}$, a weight gain is observed for both samples, indicating that the $\mathrm{SiC}$ nanowire sample is further oxidized. The oxidation is more evident for the A3 sample, of which the residual mass is 105.54\% (Figure 9a). In this case, the sample contains $\mathrm{Al}$ with a lower melting point $\left(660^{\circ} \mathrm{C}\right)$, while the content of amorphous $\mathrm{Si}-\mathrm{O}-\mathrm{Al}$ is high and easily oxidized, which is reflected by the weight gain. N3 samples showed a relatively low rate of mass change. This is because the excess carbon in the PCS precursor is consumed by the trace of oxygen, forming a thin amorphous layer of carbon on the surface of the nanowire [35]. It can be observed from the TEM image that there is an amorphous carbon layer on the surface of SiC nanowires, and the oxidation of the amorphous carbon layer will consume and result in weight loss. Meanwhile, the weight gain and mass cancellation of the amorphous crystallites and $\mathrm{Si}-\mathrm{O}-\mathrm{C}$ occur during the oxidation process. $\mathrm{N} 3$ shows absorption peaks at $566.69^{\circ} \mathrm{C}$, while the adsorption peak of $\mathrm{A} 3$ appears at $654.40{ }^{\circ} \mathrm{C}$ (Figure $9 \mathrm{~b}$ ). In addition, a peak appears at $1170.36{ }^{\circ} \mathrm{C}$, likely due to the introduction of $\mathrm{Al}$. Therefore, the thermal stability of the oxidizing substance has a great influence on the thermal stability of the nanowire at high temperatures. 


\section{Conclusions}

1. $\mathrm{SiC}$ nanowires with pearl-chain-like morphology were prepared using $\mathrm{Al}_{2} \mathrm{O}_{3}$ as catalyst. Straight $\mathrm{SiC}$ nanowires were prepared with $\mathrm{Ni}$ as catalyst. The crystallinity of pearl-chain-like nanowires is slightly higher than that of straight nanowires. The results showed that the efficiency of the nanowires formation depends on the thickness of the catalyst film. Moreover, for the both $\mathrm{SiC}$ nanowire samples, the generation of twin structural defects was noticed.

2. The main mechanism governing the formation of $\mathrm{SiC}$ nanowires in the presence of $\mathrm{Al}_{2} \mathrm{O}_{3}$ is the OAG mechanism. In this case, the growth of nanowires is mainly controlled by the amorphous $\mathrm{Si}-\mathrm{O}-\mathrm{Al}$ coated on the surface of the nanowires while the pearl-like beads are generated due to the twin defects. The SiC nanowires grown in the presence of Ni catalyst follow the VLS mechanism. As the temperature increases, and in the presence of the catalyst, the crystallization of $\mathrm{SiC}$ is favored, generating the final nanowire structure.

3. $\mathrm{SiC}$ nanowire samples prepared with two different catalysts have emissions peaks in the visible range at 395 and $465 \mathrm{~nm}$. The emission peaks blue shifted in comparison with the conventional micro-size $\mathrm{SiC}$ due to the nanosized dimension of the SiC nanowires, twin defects, and amorphous phases are identified in the samples.

4. The two samples have good thermal stability under $1000{ }^{\circ} \mathrm{C}$ in air atmosphere. Beyond this temperature, the mass of the material begins to change as a result of some slight oxidation of the material.

Author Contributions: C.G. designed and completed the experiment, summarized and sorted the data, and finished writing the paper. L.C. provided his ideas for the experiment and made some constructive comments on the paper. F.Y. reviewed the article. Q.Z. collate data and proofread manuscripts. All authors have read and agreed to the published version of the manuscript.

Funding: This work was supported by: National Natural Science Foundation of China No. 51632007, 51602258, 51872229 and 51521061; 111 Project of China No. B08040; National Science and Technology Major Project No. 2017-I-0007-0077.

Conflicts of Interest: The authors declare no conflict of interest.

\section{References}

1. Zhang, H.; Ding, W.; He, K.; Li, M. Synthesis and Characterization of Crystalline Silicon Carbide Nanoribbons. Nanoscale Res. Lett. 2010, 5, 1264-1271. [CrossRef]

2. Li, S.; Wang, N.; Zhao, H.; Du, L. Synthesis and electrical properties of p-type 3C-SiC nanowires. Mater. Lett. 2014, 126, 217-219. [CrossRef]

3. Wang, H.; Lin, L.; Yang, W.; Xie, Z.; An, L. Preferred Orientation of SiC Nanowires Induced by Substrates. J. Phys. Chem. C 2012, 114, 2591-2594. [CrossRef]

4. Chang, J.; Zhang, Q.; Lin, Y.; Shao, P.; Pei, Y.; Zhong, S.; Wu, G. Thermal management applied laminar composites with $\mathrm{SiC}$ nanowires enhanced interface bonding strength and thermal conductivity. Nanoscale 2019, 11, 15836-15845. [CrossRef]

5. YYang, G.Z.; Cui, H.; Sun, Y.; Gong, L.; Chen, J.; Jiang, D.; Wang, C.X. Simple Catalyst-Free Method to the Synthesis of beta-SiC Nanowires and Their Field Emission Properties. J. Phys. Chem. C 2009, 113, 15969-15973. [CrossRef]

6. Vorotilo, S.; Levashov, E.A.; Potanin, A.Y.; Loginov, P.A.; Shvyndina, N.V. Features of synthesizing ceramic composites discretely reinforced by carbon fibers and $\mathrm{SiC}$ nanowires formed in situ in the combustion wave. Russ. J. Non Ferr. Met. 2020, 61, 559-570. [CrossRef]

7. Wei, J.; Li, X.; Wang, Y.; Chen, B.; Zhang, M.; Qin, C. Photoluminescence property of inexpensive flexible $\mathrm{SiC}$ nanowires membrane by electrospinning and carbothermal reduction. J. Am. Ceram. Soc. 2020, 103, 6187-6197. [CrossRef]

8. Prakash, J.; Dasgupta, K.; Tripathi, B.M.; Bahadur, J.; Ghosh, S.K.; Chakravartty, J.K. A new approach to fabricate $\mathrm{SiC}$ nanowire-embedded dense SiC matrix/carbon fiber composite. J. Mater. Sci. 2014, 49, 6784-6792. [CrossRef] 
9. Dong, Y.; Fan, X.; Wei, H.; Hou, H.; Li, M.; Qu, Q.; Yin, X.; Cheng, L.; Zhang, L. Enhanced electromagnetic wave absorption properties of a novel $\mathrm{SiC}$ nanowires reinforced $\mathrm{SiO} / 3 \mathrm{Al} 2 \mathrm{O} 3 \cdot 2 \mathrm{SiO} 2$ porous ceramic. Ceram. Int. 2020, 46, 22474-22481. [CrossRef]

10. Kuang, J.; Xiao, T.; Zheng, Q.; Xiong, S.; Wang, Q.; Jiang, P.; Liu, W.; Cao, W. Dielectric permittivity and microwave absorption properties of transition metal $\mathrm{Ni}$ and $\mathrm{Mn}$ doped $\mathrm{SiC}$ nanowires. Ceram. Int. 2020, 46, 12996-13002. [CrossRef]

11. Zhu, S.; Xi, H.-A.; Li, Q.; Wang, R. In situ growth of beta-SiC nanowires in porous SiC ceramics. J. Am. Ceram. Soc. 2005, 88, 2619-2621. [CrossRef]

12. Pan, J.-M.; Yan, X.; Cheng, X.-N.; Lu, Q.-B.; Wang, M.-S.; Zhang, C.-H. Preparation of SiC nanowires-filled cellular SiCO ceramics from polymeric precursor. Ceram. Int. 2012, 38, 6823-6829. [CrossRef]

13. Makeev, M.A.; Srivastava, D.; Menon, M. Silicon carbide nanowires under external loads: An atomistic simulation study. Phys. Rev. B 2006, 74, 165303. [CrossRef]

14. Zhang, R.Q.; Lifshitz, Y.; Lee, S.T. Oxide-Assisted Growth of Semiconducting Nanowires. Adv. Mater. 2010, 15, 635-640. [CrossRef]

15. Kang, J.-H.; Krizek, F.; Załuska-Kotur, M.A.; Krogstrup, P.; Kacman, P.; Beidenkopf, H.; Shtrikman, H. Au-Assisted Substrate-Faceting for Inclined Nanowire Growth. Nano Lett. 2018, 18, 4115-4122. [CrossRef]

16. Zhang, X.; Chen, Y.; Xie, Z.; Yang, W. Shape and Doping Enhanced Field Emission Properties of Quasialigned 3C-SiC Nanowires. J. Phys. Chem. C 2010, 114, 8251-8255. [CrossRef]

17. Wang, H.; Zhang, X.; Lee, C.-S.; Zou, K.; Shi, W.S.; Wu, S.K.; Chang, J.; Lee, S.T. Oxide Shell Assisted VaporLiquidSolid Growth of Periodic Composite NanowiresA Case of Si/Sn. Chem. Mater. 2007, 19, 5598-5601. [CrossRef]

18. Agati, M.; Amiard, G.; Le Borgne, V.; Castrucci, P.; Dolbec, R.; De Crescenzi, M.; El Khakani, M.A.; Boninelli, S. Growth Mechanisms of Inductively-Coupled Plasma Torch Synthesized Silicon Nanowires and their associated photoluminescence properties. Sci. Rep. 2016, 5, 37598. [CrossRef]

19. Xu, X.; Li, S.; Wang, Y.; Fan, T.; Jiang, Y.; Huang, L.; He, Q.; Ao, T. Silicon nanowires prepared by electron beam evaporation in ultrahigh vacuum. Nanoscale Res. Lett. 2012, 7, 243. [CrossRef]

20. Shi, W.S.; Zheng, Y.F.; Wang, N.; Lee, C.-S.; Lee, S.-T. A General Synthetic Route to III-V Compound Semiconductor Nanowires. Adv. Mater. 2001, 13, 591-594. [CrossRef]

21. Wang, Y.; Cheng, Y.; Wang, Y.; Zhang, S.; Zhang, X.; Yin, S.; Wang, M.; Xia, Y.; Li, Q.; Zhao, P.; et al. Oxide-assisted growth of scalable single-crystalline graphene with seamlessly stitched millimeter-sized domains on commercial copper foils. RSC Adv. 2018, 8, 8800-8804. [CrossRef]

22. Zhang, Y.F.; Tang, Y.; Wang, N.; Yu, D.P.; Lee, C.-S.; Bello, I.; Lee, S.T. Silicon nanowires prepared by laser ablation at high temperature. Appl. Phys. Lett. 1998, 72, 1835-1837. [CrossRef]

23. Jiang, Y.; Meng, X.-M.; Liu, J.; Hong, Z.-R.; Lee, C.-S.; Lee, S.-T. ZnS Nanowires with Wurtzite Polytype Modulated Structure. Adv. Mater. 2003, 15, 1195-1198. [CrossRef]

24. Gudiksen, M.S.; Lauhon, L.J.; Wang, J.; Smith, D.C.; Lieber, C.M. Growth of nanowire superlattice structures for nanoscale photonics and electronics. Nature 2002, 415, 617-620. [CrossRef]

25. Björk, M.; Ohlsson, B.J.; Sass, T.; Persson, A.I.; Thelander, C.; Magnusson, M.; Deppert, K.; Wallenberg, L.R.; Samuelson, L. One-dimensional Steeplechase for Electrons Realized. Nano Lett. 2002, 2, 87-89. [CrossRef]

26. Wu, Y.; Messer, B.; Yang, P. Superconducting MgB 2 Nanowires. Adv. Mater. 2001, 13, 1487-1489. [CrossRef]

27. Craats, A.M.V.D.; Warman, J.M. The Core-Size Effect on the Mobility of Charge in Discotic Liquid Crystalline Materials. Adv. Mater. 2001, 13, 130-133. [CrossRef]

28. Yu, Z.; Luo, J.; Harmer, M.P.; Zhu, J. An Order-Disorder Transition in Surface Complexions and Its Influence on Crystal Growth of Boron-Rich Nanostructures. Cryst. Growth Des. 2015, 15, 3547-3551. [CrossRef]

29. Chiu, S.C.; Li, Y.Y. SiC nanowires in large quantities: Synthesis, band gap characterization, and photoluminescence properties. J. Cryst. Growth 2009, 311, 1036-1041. [CrossRef]

30. Wang, X.J.; Tian, J.F.; Bao, L.H.; Hui, C.; Yang, T.Z.; Shen, C.M.; Gao, H.-J. Large scale SiC/SiOx nanocables: Synthesis, photoluminescence, and field emission properties. J. Appl. Phys. 2007, 102, 56. [CrossRef]

31. Li, Z.; Zhang, J.; Meng, A.; Guo, J. Large-area highly-oriented SiC nanowire arrays: Synthesis, Raman, and photoluminescence properties. J. Phys. Chem. B 2006, 110, 22382-22386. [CrossRef] [PubMed]

32. Wu, R.; Pan, Y.; Yang, G.; Gao, M.; Wu, L.; Chen, J.; Zhai, R.; Lin, J. Twinned SiC Zigzag Nanoneedles. J. Phys. Chem. C 2007, 111, 6233-6237. [CrossRef] 
33. Xi, G.; Peng, Y.; Wan, S.; Li, T.; Yu, W.; Qian, Y. Lithium-Assisted Synthesis and Characterization of Crystalline 3CSiC Nanobelts. J. Phys. Chem. B 2004, 108, 20102-20104. [CrossRef]

34. Yu, Z.; Fu, X.; Yuan, J.; Lea, S.; Harmer, M.P.; Zhu, J. Correlating Growth Habit of Boron-Rich Low-Dimensional Materials with Defect Structures by Electron Microscopy. Cryst. Growth Des. 2013, 13, 2269-2276. [CrossRef]

35. Song, Q.; Yan, H.; Liu, K.; Xie, K.; Li, W.; Gai, W.; Chen, G.; Li, H.; Shen, C.; Fu, Q.; et al. Vertically Grown Edge-Rich Graphene Nanosheets for Spatial Control of Li Nucleation. Adv. Energy Mater. 2018, 8, 1800564. [CrossRef]

Publisher's Note: MDPI stays neutral with regard to jurisdictional claims in published maps and institutional affiliations.

(C) 2020 by the authors. Licensee MDPI, Basel, Switzerland. This article is an open access article distributed under the terms and conditions of the Creative Commons Attribution (CC BY) license (http://creativecommons.org/licenses/by/4.0/). 